\title{
Charcot-Marie-Tooth disease type 4E
}

INSERM

\section{Source}

INSERM. (1999). Orphanet: an online rare disease and orphan drug data base. CharcotMarie-Tooth disease type 4E. ORPHA:99951

Charcot-Marie-T ooth disease type 4E (CMT4E) is a congenital, hypomyelinating subtype of Charcot-Marie-T ooth disease type 4 characterized by a Dejerine-Sottas syndrome-like phenotype (incl. hypotonia and/or delayed motor development in infancy), extremely slow nerve conduction velocities, potential respiratory dysfunction, cranial nerve involvement, and the typical CMT phenotype, i.e. distal muscle weakness and atrophy, sensory loss, and foot deformity. 